Review

\title{
Nivolumab as Programmed Death-1 (PD-1) Inhibitor for Targeted Immunotherapy in Tumor
}

\author{
Liting Guo, Haijun Zhang, Baoan Chen ${ }^{\bowtie}$ \\ Department of Hematology and Oncology (Key Department of Jiangsu Medicine), The Affiliated Zhongda Hospital, Medical School of Southeast University, \\ Nanjing. \\ $\triangle$ Corresponding author: Baoan Chen. Department of Hematology and Oncology (Key Department of Jiangsu Medicine), The Affiliated Zhongda Hospital, \\ Medical School of Southeast University, Dingjiaqiao 87, Gulou District, Nanjing 210009, Jiangsu Province, People's Republic of China. Tel +86 2583272006 Fax \\ +862583272011 Email cba8888@hotmail.com. \\ (c) Ivyspring International Publisher. This is an open access article distributed under the terms of the Creative Commons Attribution (CC BY-NC) license \\ (https://creativecommons.org/licenses/by-nc/4.0/). See http://ivyspring.com/terms for full terms and conditions.
}

Received: 2016.08.09; Accepted: 2016.10.13; Published: 2017.02.10

\begin{abstract}
Targeted immunotherapy has become the most promising approach for tumor patients. Programmed death-1 (PD-1), an inhibitory receptor expressed on activated T cells, can reverse immune suppression and release T cell activation. Nivolumab, a fully human immunoglobulin G4 PD-1 immune checkpoint inhibitor antibody, blocks PD-1 and promotes antitumor immunity, and it is effective for treating non-small-cell lung cancer (NSCLC), melanoma, renal cell carcinoma (RCC) and other cancers. The present review summarizes the efficacy and current status of clinical trials of nivolumab and that enabled nivolumab to be investigated in patients.
\end{abstract}

Key words: nivolumab, programmed death-1 inhibitor, targeted immunotherapy.

\section{Introduction}

Targeted immunotherapy as a potential treatment for cancer has been intensively studied over the past decade based on the concept of the underlying principles of tumor biology and immunology [1,2]. Cancer immunotherapy comprises a variety of treatment approaches, including active immunotherapeutic strategies, such as cancer vaccines, and passive immunotherapies, such as monoclonal antibodies (mAbs) or adoptive transfer of tumor-specific T cells [3-5]. Tumor cells often involve in multiple resistance mechanisms that they may evade the host-tumor immune system $[4,6,7]$. However, immune system checkpoint inhibitors that mediate $\mathrm{T}$-cell response have shown significantly enhance antitumor immunity [8,9]. Cytotoxic T-lymphocyte- associated antigen 4 (CTLA-4, also known as CD152), with its ligands CD80 and CD86, an inhibitory receptor as a global immune checkpoint engaged in priming immune responses via downmodulating the initial stages of T-cell activation, was the first clinically validated checkpoint pathway target $[5,9,10]$. Programmed cell death-1 (PD-1, also known as CD279) is another inhibitory receptor expressed on activated T and B cells, which normally function to dampen the immune response [11-14]. PD-1 is engaged by ligands PD-L1 (B7-H1, CD274) and PD-L2 (B7-DC, CD273), which are expressed by tumor cells and infiltrating immune cells [10,13]. Inhibition of the interaction between PD-1 and PD-L1 can enhance anti-tumor responses, delay tumor growth, and facilitate tumor rejection $[7,15]$. Furthermore, immune checkpoint blockade facilitated tumor cell destruction is a strategy for cancer immunotherapy $[16,17]$. PD-L1 is highly selectively expressed on tumor infiltrating lymphocytes (TILs) from many tumors $[7,8]$. The recent preclinical and clinical data have shown that PD-L1 expression is associated with worse prognosis in renal cell carcinoma (RCC) and non-small-cell lung cancer (NSCLC), while with good prognosis in melanoma [18].

Nivolumab (BMS-936558, ONO-4538, or MDX1106, trade name Opdivo; Bristol-Myers Squibb, Princeton, NJ, USA) is the first-in-human immunoglobulin G4 (IgG4) PD-1 immune checkpoint inhibitor antibody that disrupts the interaction of the 
PD-1 receptor with its ligands PD-L1 and PD-L2, thereby inhibiting the cellular immune response $[14,15,19]$. The anti-PD-1 antibody nivolumab was approved by the US Food and Drug Administration (FDA) for the treatment of melanoma in 2014 and RCC in 2015, nivolumab also has received the FDA approval in March 2015 for squamous lung cancer treatment, and on October 9, 2015, the FDA expanded the nivolumab for metastatic NSCLC [20-22]. We now report the mechanism, pharmacokinetics, and pharmacogenetics of nivolumab, in addition to further clinical experiences of nivolumab in the treatment of NSCLC and other cancers.

\section{Generation and mechanism}

Nivolumab is a genetically engineered anti-PD-1 $\mathrm{mAb}$, developed by immunizing transgenic mice for human immunoglobulin loci with recombinant Chinese hamster ovary cells expressing human PD-1 and PD-1/human IgG1 Fc fusion protein $[4,23,24]$. Nivolumab contains a hinge region mutation (S228P), the S228P mutation reduces Fc exchange with serum IgG4 molecules to improve stability and reduce therapeutic variability [24]. Nivolumab binds PD-1 with high affinity $\left(K_{D}=2.6 \mathrm{nmol} / \mathrm{L}\right.$ by Scatchard analysis to polyclonally activated human $\mathrm{T}$ cells), blocks its interactions with both PD-L1 and PD-L2, and stimulates memory response to tumor antigen-specific T cell proliferation (Figure 1) [4,24].

\section{Pharmacokinetics and pharmacodynamics}

The recommended dosage of nivolumab is 3.0 $\mathrm{mg} / \mathrm{kg}$ administered intravenously over 60 minutes every 2 weeks until disease progression or unacceptable toxicity $[25,26]$. Nivolumab has linear pharmacokinetics (PK), with a dose-proportional increase in the maximum concentration (Cmax) and area under the concentration-time curve (AUC) $[4,15,23]$. Based upon the study of Brahmer et al, the median time to the peak concentration of nivolumab was 1-4 hours after the start of infusion, and serum half-life $\left(\mathrm{t}_{1 / 2}\right)$ was 12 days $(0.3,1.0$ or $3.0 \mathrm{mg} / \mathrm{kg})$ to 20 days $(10.0 \mathrm{mg} / \mathrm{kg})[4,23,24]$. The pharmacodynamics (PD) of nivolumab was evaluated according to PD-1 receptor occupancy on circulating $\mathrm{CD}^{+} \mathrm{T}$ cells (Figure 2) [15]. PD-1 occupancy appeared to be dose-independent, with a mean peak occupancy of $85 \%$ at $4-24$ hours and average plateau occupancy of $72 \%$ observed at 57 days and beyond [4]. In addition, the median PD-1 receptor occupancy rate by nivolumab treatment was $64 \%-70 \%$ for 65 patients with melanoma in peripheral blood mononuclear cells (PBMCs), who were treated with one cycle of nivolumab at a dose of 0.1 to $10.0 \mathrm{mg} / \mathrm{kg}$ every 2 weeks [15]. All these data indicated nivolumab has a high affinity for PD-1 [4,15,23-27].

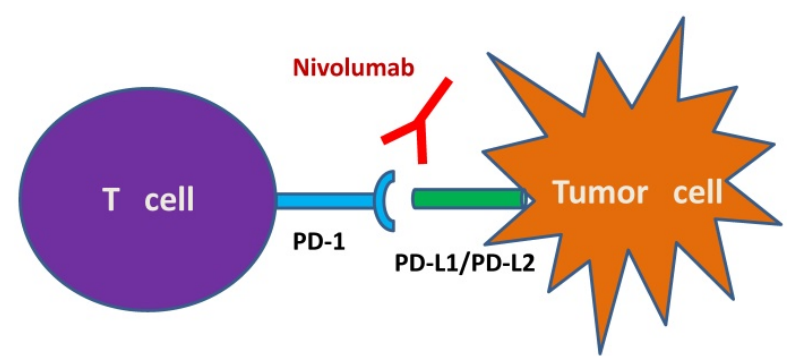

Figure 1. Schematic illustration of the mechanism of nivolumab as IgG4 PD-1 immune checkpoint inhibitor antibody. Notes: Nivolumab prevents the binding of PD-1 to its ligands PD-L1 and PD-L2. This binding releases PD-1 pathway mediated immune responses against tumor cells. Abbreviations: IgG4, immunoglobulin G4; PD-1, programmed death-1; PD-L1, programmed death ligand-1; PD-L2, programmed death ligand-2.

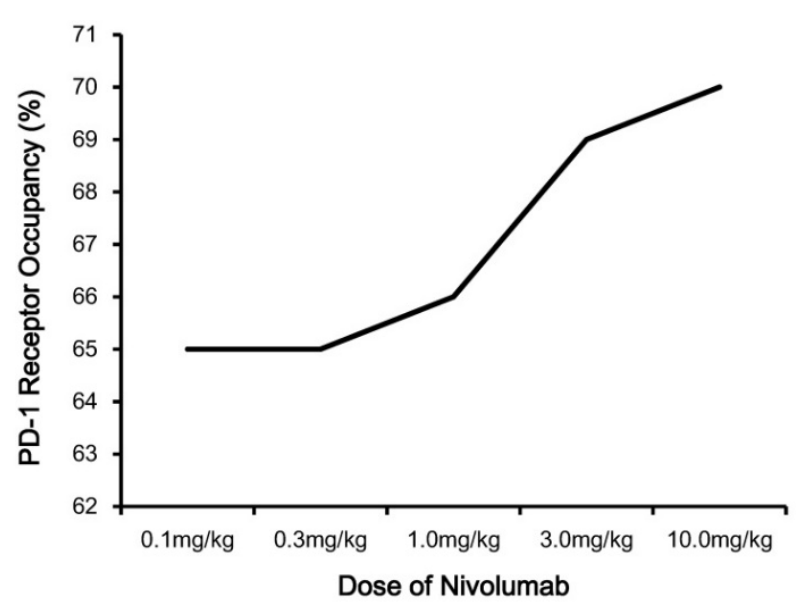

Figure 2. Pharmacodynamics of nivolumab. Notes: PD-1 occupancy on circulating CD3 $+\mathrm{T}$ cells after one infusion of nivolumab is shown for patients each receiving $0.1,0.3,1.0,3.0$ or $10.0 \mathrm{mg} / \mathrm{kg}$. Abbreviations: PD-1, programmed death-1.

\section{Clinical trials}

The efficacy of nivolumab for the treatment of tumors has been investigated in several clinical trials, including various Phase I, II, and III studies on registry (Table 1).

\section{Phase I}

\section{Nivolumab in lung cancer}

Lung cancer is the leading cause of cancer death, approximately $27 \%$ of all annual cancer deaths in the world [28]. NSCLC represents $85 \%$ of all lung cancers and can be divided in two histological subgroups: squamous cell and non-squamous cell lung cancer [29]. Immunosurveillance mechanisms as new models of immunology have recently developed new generation of immune modulators in NSCLC, particularly for patients with squamous cell disease $[29,30]$. Encouragingly, the advent of immunotherapy in lung cancer is entering a new era [29]. The first 
in-human phase I nivolumab trail, was designed as an open-label multi-institutional study [4]. The trial consisted of a subgroup of 39 patients with refractory solid tumors including NSCLC, advanced metastatic melanoma, colorectal cancer (CRC), castrateresistant prostate cancer (CRPC), and RCC [4,24]. Patients were treated with intravenous (iv.) dose of nivolumab at $0.3,1.0,3.0$ or $10.0 \mathrm{mg} / \mathrm{kg}$. Nivolumab was well tolerated, no dose-limiting toxicities were observed after one dose, and the maximum tolerated dose was not defined $[4,28]$. Based on these promising data, an expanded cohort of patients with advanced melanoma, NSCLC, CRPC, RCC or CRC was subsequently enrolled [15]. The expansion trial recruited 296 patients, and consisted of 122 patients with NSCLC. NSCLC patients treated with nivolumab at a dose of $1.0,3.0$, and $10.0 \mathrm{mg} / \mathrm{kg}$, the objective response rate (ORR) was $6 \%, 32 \%$, and $18 \%$, respectively [15]. Updated results presented in abstract, median overall survival (mOS) was 9.2 months and 9.6 months for squamous and non-squamous NSCLC, respectively [31]. Adverse events (AEs) were also observed, the most common grade 3 or 4 AEs were fatigue, pneumonitis, and elevated AST (2\% each) [15,31]. In an expansion cohort of the Phase I study in previously treated NSCLC patients, the mOS was 9.2-14.9 months $[32,33]$. In this phase I of Gettinger et al, they reported the results of first-line nivolumab in chemotherapy-naïve advanced NSCLC [34]. The ORR was $30 \%$, and the median progression-free survival (mPFS) was 29.6\%. Interesting, also in Gettinger et al study, 129 patients with heavily pretreated advanced NSCLC received nivolumab $(1.0,3.0$, or $10.0 \mathrm{mg} / \mathrm{kg}$ ) intravenously once every 2 weeks, the mOS was 9.9 months [14]. A total of 56 patients with advanced NSCLC were enrolled and the phase I trial assigned by Antonia et al, it focused on platinum-based doublet chemotherapy (PT-DC) in advanced NSCLC. The ORR was 33\% (nivolumab $10 \mathrm{mg} / \mathrm{kg}$ (N10) + gemcitabine (gem) / cisplatin (cis) [squamous (sq)]), $47 \%$ (N10 + pemetrexed (pem) /cis [non-sq]), 47\% $(\mathrm{N} 10+$ paclitaxel (pac) / carboplatin (carb) $[\mathrm{sq}+$ non-sq]) and 43\% (nivolumab $5 \mathrm{mg} / \mathrm{kg}$ (N5) + pac/carb [sq + non-sq]), respectively [35].

Table 1. Characteristics of main clinical trials of nivolumab for targeted immunotherapy in tumor.

\begin{tabular}{|c|c|c|c|c|}
\hline Study & Trial & Design & Tumor type & Outcomes \\
\hline Topalian et al [15] & Phase I (2012) & Dose-escalation & $\begin{array}{l}\text { Advanced melanoma, NSCLC, RCC, CRPC, } \\
\text { or CRC }\end{array}$ & $\begin{array}{l}\text { RR } \\
\text { NSCLC: } 18 \% \\
\text { Melanoma: } 28 \% \\
\text { RCC: } 27 \%\end{array}$ \\
\hline Brahmer et al [32] & Phase I (2014) & Dose-escalation & Previously treated advanced NSCLC & mOS: 9.2-14.9 months \\
\hline Gettinger et al [34] & Phase I (2014) & First-line & Chemotherapy-naïve advanced NSCLC & $\begin{array}{l}\text { ORR: } 30 \% \\
\text { mPFS: } 29.6 \%\end{array}$ \\
\hline Gettinger et al [14] & Phase I (2015) & Dose-escalation & Heavily pretreated advanced NSCLC & $\begin{array}{l}\text { mOS: } 9.9 \text { months } \\
\text { ORR: } 17 \%\end{array}$ \\
\hline Topalian et al [13] & Phase I (2014) & Dose-escalation & Advanced melanoma & $\begin{array}{l}\text { mOS: } 16.8 \text { months } \\
\text { mPFS: } 3.7 \text { months }\end{array}$ \\
\hline Drake et al [44] & Phase I (2013) & Dose-escalation & Previously treated mRCC & Median duration of response: 12.9 months \\
\hline Ansell et al [47] & Phase I (2015) & Dose-escalation & Relapsed or refractory Hodgkin's lymphoma & RR: $87 \%$ \\
\hline Rizvi et al [48] & Phase II (2015) & Single-arm & Advanced, refractory squamous NSCLC & $\begin{array}{l}\text { mPFS: } 1.9 \text { months } \\
\text { mOS: } 8.2 \text { months }\end{array}$ \\
\hline Postow et al [49] & Phase II (2015) & Double-blinded & Untreated metastatic melanoma & $\begin{array}{l}\text { ORR } \\
\text { nivolumab and ipilimumab: } 61 \% \\
\text { ipilimumab and placebo: } 11 \%\end{array}$ \\
\hline Motzer et al [50] & Phase II (2015) & $\begin{array}{l}\text { Blinded, randomized, } \\
\text { multicenter }\end{array}$ & Previously treated mRCC & $\begin{array}{l}\text { mPFS } \\
0.3 \mathrm{mg} / \mathrm{kg}: 2.7 \text { months } \\
2 \mathrm{mg} / \mathrm{kg}: 4.0 \text { months } \\
10 \mathrm{mg} / \mathrm{kg}: 4.2 \text { months }\end{array}$ \\
\hline Hamanishi et al [51] & Phase II (2015) & Dose-escalation & Platinum-resistant ovarian cancer & $\begin{array}{l}\text { mPFS: } 3.5 \text { months } \\
\text { mOS: } 20.0 \text { months }\end{array}$ \\
\hline Brahmer et al [52] & Phase III (2015) & $\begin{array}{l}\text { Randomized, open-label, } \\
\text { international }\end{array}$ & Advanced squamous NSCLC & $\begin{array}{l}\text { mOS } \\
\text { nivolumab: } 9.2 \text { months } \\
\text { docetaxel: } 6.0 \text { months }\end{array}$ \\
\hline Robert et al [54] & Phase III (2015) & $\begin{array}{l}\text { Randomized, open-label, } \\
\text { international }\end{array}$ & $\begin{array}{l}\text { Previously untreated melanoma without } \\
\text { BRAF mutation }\end{array}$ & $\begin{array}{l}\text { ORR } \\
\text { nivolumab: } 40.0 \% \\
\text { dacarbazine: } 13.9 \%\end{array}$ \\
\hline Larkin et al [56] & Phase III (2015) & Randomized, double-blind & $\begin{array}{l}\text { Untreated unresectable stage III or IV } \\
\text { melanoma }\end{array}$ & $\begin{array}{l}\text { mPFS } \\
\text { nivolumab plus ipilimumab: } 11.5 \text { months } \\
\text { ipilimumab: } 2.9 \text { months } \\
\text { nivolumab: } 7.0 \text { months }\end{array}$ \\
\hline Motzer et al [58] & Phase III (2015) & Randomized, open-label & Previously treated advanced RCC & $\begin{array}{l}\text { mOS } \\
\text { nivolumab: } 25.0 \text { months } \\
\text { everolimus: } 19.6 \text { months }\end{array}$ \\
\hline
\end{tabular}

Abbreviations: CRC, colorectal cancer; CRPC, castrateresistant prostate cancer; NSCLC, non-small-cell lung cancer; RCC, renal-cell cancer; ORR, objective response rate; RR, response rates; mOS, median overall survival; mPFS, median progression-free survival; mRCC, metastatic renal cell carcinoma. 


\section{Nivolumab in melanoma}

Melanoma represents less common than other skin cancers, but the fatality rate is higher [36]. Malignant melanoma has frequent metastatic property, and highly been resistant to conventional cytotoxic chemotherapy. However, with the recent emergence of immune checkpoint inhibitors and molecular-targeted agents, the therapeutic landscape for advanced melanoma has recently changed considerably [36,37]. The phase I clinical trial of Topalian et al studied the effects of nivolumab for 296 patients, of 94 patients with melanoma, the PFS was $41 \% \quad[15,23,37]$. Another dose-escalation, cohort expansion study evaluated the antitumor activity and safety phase I trial tested nivolumab in 107 melanoma patients [13]. Patients administered intravenously once every 2 weeks, setting in 8-week treatment cycles at the dose of $1.0,3.0$, or $10.0 \mathrm{mg} / \mathrm{kg}$. The mPFS was 3.7 months [13,37]. In the third phase I study, 90 patients with vaccine in ipilimumab-refractory or -naive melanoma received nivolumab at 1.0, 3.0, or $10.0 \mathrm{mg} / \mathrm{kg}$, with or without a multipeptide vaccine [38]. Among 87 evaluable patients, the ORR for nivolumab with or without vaccine was $25 \%[38,39]$. Wolchok et al also conducted a phase I trial of nivolumab combined with ipilimumab in patients with advanced melanoma, all 86 patients were enrolled in the study [40]. In the concurrent-regimen group, 53 patients received nivolumab and ipilimumab every 3 weeks for four doses and nivolumab alone, the ORR was $40 \%$. In the sequenced-regimen cohorts, 33 patients pretreated with ipilimumab received nivolumab every 2 weeks, the ORR was $20 \%[39,40]$.

\section{Nivolumab in RCC}

RCC is the third most common cause of urological malignancy in the world [41]. Unfortunately, RCC is largely resistant to radiation and chemotherapy, RCC mortality rates have steadily increased [41,42]. However, in recent years, molecularly targeted therapies shift the traditional treatment mode of RCC, including nivolumab [42]. In the initial Phase I trial of nivolumab published by Brahmer et al, two (RCC and melanoma) PRs were observed [4,24,43]. Another Phase I trial, 34 previously treated patients with metastatic RCC (mRCC) received nivolumab at the 1.0 and 10.0 $\mathrm{mg} / \mathrm{kg}$ dose levels [44]. The median duration of response was 12.9 months $[24,43,44]$.

\section{Nivolumab in Hodgkin's lymphoma}

Classical Hodgkin's lymphoma accounts for approximately $10 \%$ of all malignant lymphomas, however, $25 \%$ of them experience either primary or secondary chemorefractoriness or disease relapse [45]. Fortunately, nivolumab could inhibit immune evasion by the PD-1 pathway with Reed-Sternberg cells in Hodgkin's lymphoma [46]. Increasing preclinical and clinical research have demonstrated that nivolumab has substantial therapeutic activity and a satisfactory safety profile [46,47]. In this ongoing phase I trial, 23 patients with relapsed or refractory Hodgkin's lymphoma treated with nivolumab at the dose of 1.0 or $3.0 \mathrm{mg} / \mathrm{kg}$ for a maximum of 2 years [47]. The response rate (RR) was $87 \%$, with a CR of $17 \%$, a PR of $70 \%$, and stable disease of $13 \%$ [47].

\section{Phase II}

\section{Nivolumab in lung cancer}

Based on these Phase I data, a randomized single-arm Phase II trial was launched to assess activity and safety of nivolumab for patients with advanced, refractory squamous NSCLC [48]. 117 patients with histologically or cytologically documented stage IIIB or IV squamous NSCLC were treated with a dose of $3.0 \mathrm{mg} / \mathrm{kg}$ according to the results of Phase I trials. The results showed that mPFS was 1.9 months, and mOS was 8.2 months, AEs was consistent with the phase 1 trial $[28,48]$.

\section{Nivolumab in melanoma}

A double-blind phase II trial involving 142 patients with previously untreated metastatic melanoma were randomly assigned (2:1) to combination therapy (nivolumab and ipilimumab) and ipilimumab monotherapy (ipilimumab and placebo) [23,49]. Among patients with BRAF wild-type tumors, the ORR was $61 \%$ in the combination group versus $11 \%$ in the ipilimumab monotherapy group [49]. The mPFS of combination therapy was not reached and ipilimumab monotherapy was 4.4 months [49].

\section{Nivolumab in RCC}

Based on evidence of activity in the phase I trial, a blinded, randomized, multicenter phase II trial by Motzer et al investigated the activity and safety of nivolumab in patients with previously treated mRCC [24,50]. In the study, 168 patients were randomized to the nivolumab $0.3,2.0$, and $10.0 \mathrm{mg} / \mathrm{kg}$. As expected, the mPFS were $2.7,4.0$, and 4.2 months, the ORR was $20 \%, 22 \%$, and $20 \%$, the mOS was $18.2,25.5$, and 24.7 months, respectively [50].

\section{Nivolumab in ovarian cancer}

A Phase II trial was to determine the safety and antitumor activity of nivolumab in patients with platinum-resistant ovarian cancer $[24,51]$. The efficacy population consisted of 20 patients treated with an 
intravenous infusion of nivolumab at a dose of 1.0 or $3.0 \mathrm{mg} / \mathrm{kg}$ every 2 weeks [51]. The mPFS was 3.5 months, and the mOS was 20.0 months [51].

\section{Phase III}

\section{Nivolumab in lung cancer}

In Brahmer et al open-label, randomized, international, phase 3 trial, 272 patients received nivolumab intravenously as monotherapy $(3 \mathrm{mg} / \mathrm{kg}$ every 2 weeks) or docetaxel $\left(75 \mathrm{mg} / \mathrm{m}^{2}\right.$ every 3 weeks) [52]. The mOS was 9.2 months with nivolumab versus 6.0 months with docetaxel, the mPFS of the nivolumab group was 3.5 months versus 2.8 months of the docetaxel group [52,53].

\section{Nivolumab in melanoma}

Recently, the results of three international, randomized Phase III studies of nivolumab were conducted [54,55,56]. The first Phase III trial (CheckMate 066) compared nivolumab with dacarbazine in 418 previously untreated patients who had metastatic melanoma without a BRAF mutation $[23,54]$. The OS rate was obviously higher in patients treated with nivolumab as compared with dacarbazine [54]. In the second reported phase III nivolumab trial, Weber et al enrolled 631 patients with advanced melanoma who progressed after anti-CTLA-4 treatment, randomly allocating 272 patients given nivolumab and 133 given investigator's choice of chemotherapy (ICC) $[55,57]$. The ORR was $31.7 \%$ in the nivolumab group, and $10.6 \%$ in the ICC group [55]. The third Phase III trial (CheckMate 067), nivolumab alone or nivolumab plus ipilimumab was compared with ipilimumab alone in 945 previously untreated patients with unresectable stage III or IV melanoma [56]. The mPFS of nivolumab plus ipilimumab, ipilimumab and nivolumab was 11.5 months, 2.9 months, and 7.0 months, respectively [56].

\section{Nivolumab in RCC}

In the phase III by Motzer et al, 821 patients with advanced RCC were randomly allocated to either nivolumab or everolimus [58]. The mOS was 25.0 months with nivolumab compared with 19.6 months with everolimus. The mPFS was 4.6 months with nivolumab and 4.4 months with everolimus $[58,59]$.

\section{Safety assessment and durable effect}

The safety profile of nivolumab treatment is generally well tolerated. However, AEs also occurred, the most common AEs were fatigue, decreased appetite, diarrhea, nausea, cough, dyspnea, constipation, vomiting, rash, pyrexia, and headache. Common treatment-related AEs included fatigue, rash, diarrhea, pruritus, decreased appetite, and nausea [15]. The frequently occurring AEs with a potential immunologic cause were similar to the frequency observed in the clinical trials [54]. Immune-related AEs (irAEs) were of special interest because of the presumed mechanism of action of anti-PD-1 and prior experience with anti-CTLA-4 [14]. Select irAEs cause occurred most frequently in the skin, gastrointestinal, endocrine, and hepatic organ categories [49]. Additionally, nivolumab's toxicities are different than those observed with traditional chemotherapy [28], nivolumab treatment is associated with irAEs that can often be managed with corticosteroids in many cases [28]. Drug-related AEs of special interest included pneumonitis, vitiligo, colitis, hepatitis, hypophysitis, and thyroiditis [15]. Pneumonitis is a serious AE and is of major concern in lung cancer patients [30], and mild-to-moderate pneumonitis was managed successfully with either observation or glucocorticoids [15]. Hepatic or gastrointestinal AEs were managed with treatment interruption and the administration of glucocorticoids, moreover, these AEs could be reversible [15]. Endocrine disorders were treated with replacement therapy [15]. Based on indirect and direct comparisons in the patient population, grade 3 or 4 toxicities appear to be less common with nivolumab than with cytotoxic chemotherapy [28].

\section{Conclusion and Future Directions}

On the basis of these observations, nivolumab is a promising PD-1 inhibitor for targeted immunotherapy in the treatment of NSCLC, melanoma, RCC and other cancers. In addition, the clinical trials showed that nivolumab prolonged PFS, increased response rates, and is an effective and safe alternative for patients. Furthermore, nivolumab or plus nivolumab was superior to standard chemotherapy in patients with tumor. These results suggest that nivolumab has the potential as identifying predictive biomarkers for appropriate therapeutic therapy and drug development.

\section{Acknowledgments}

This work was supported by the National Nature Science Foundation of the People's Republic of China (numbers 81370673), and the Key Medical Projects of Jiangsu Province (numbers BL2014078), and Key Discipline of Jiangsu Province (2011- 2015).

\section{Conflict of interest}

The authors report no conflicts of interest in this work. 


\section{References}

1. Kirkwood JM, Butterfield LH, Tarhini AA, Zarour H, Kalinski P, Ferrone S. Immunotherapy of cancer in 2012. CA Cancer J Clin. 2012; 62(5):309-35.

2. Ledford H. Cancer treatment: The killer within. Nature. 2014; 508(7494): 24-6.

3. Topalian SL, Weiner GJ, Pardoll DM. Cancer immunotherapy comes of age. J Clin Oncol. 2011; 29(36):4828-36.

4. Brahmer JR, Drake CG, Wollner I, Powderly JD, Picus J, Sharfman WH, et al. Phase I study of single-agent anti- programmed death-1 (MDX-1106) in refractory solid tumors: safety, clinical activity, pharmacodynamics, and immunologic correlates. J Clin Oncol. 2010; 28 (19):3167-75.

5. Brahmer JR, Tykodi SS, Chow LQ, Hwu WJ, Topalian SL, Hwu P, et al. Safety and activity of anti-PD-L1 antibody in patients with advanced cancer. N Engl J Med. 2012; 366 (26): 2455- 65

6. Motzer RJ, Rini BI, McDermott DF, Redman BG, Kuzel TM, Harrison MR, et al. Nivolumab for Metastatic Renal Cell Carcinoma: Results of a Randomized Phase II Trial. J Clin Oncol. 2015; 33 (13): 1430-7.

7. Hawkes EA, Grigg A, Chong G. Programmed cell death-1 inhibition in lymphoma. Lancet Oncol. 2015; 16(5):e234-45.

8. Pardoll DM. The blockade of immune checkpoints in cancer immunotherapy. Nat Rev Cancer. 2012; 12(4):252-64.

9. Topalian SL, Taube JM, Anders RA, Pardoll DM. Mechanism-driven biomarkers to guide immune checkpoint blockade in cancer therapy. Nat Rev Cancer. 2016; 16(5):275-87.

10. Belum VR, Benhuri B, Postow MA, , Hellmann MD, Lesokhin AM, Segal NH, et al. Characterisation and management of dermatologic adverse events to agents targeting the PD-1 receptor. Eur J Cancer. 2016; 60:12-25.

11. Hamid O, Robert C, Daud A, Hodi FS, Hwu WJ, Kefford R, et al. Safety and tumor responses with lambrolizumab (anti-PD-1) in melanoma. N Engl J Med. 2013; 369(2):134-44.

12. Nishino M, Sholl LM, Hodi FS, Hatabu H, Ramaiya NH. Anti-PD-1-Related Pneumonitis during Cancer Immunotherapy. N Engl J Med. 2015; 373(3):288-90.

13. Topalian SL, Sznol M, McDermott DF, Kluger HM, Carvajal RD, Sharfman $\mathrm{WH}$, et al. Survival, durable tumor remission, and long-term safety in patients with advanced melanoma receiving nivolumab. J Clin Oncol. 2014; 32(10): 1020-30.

14. Gettinger SN, Horn L, Gandhi L, Spigel DR, Antonia SJ, Rizvi NA, et al. Overall Survival and Long-Term Safety of Nivolumab (Anti-Programmed Death 1 Antibody, BMS-936558, ONO-4538) in Patients With Previously Treated Advanced Non-Small-Cell Lung Cancer. J Clin Oncol. 2015; 33(18):2004-12

15. Topalian SL, Hodi FS, Brahmer JR, Gettinger SN, Smith DC, McDermott DF, et al. Safety, activity, and immune correlates of anti-PD-1 antibody in cancer. N Engl J Med. 2012; 366(26):2443-54

16. Wolchok JD, Kluger H, Callahan MK, Postow MA, Rizvi NA, Lesokhin AM, et al. Nivolumab plus Ipilimumab in Advanced Melanoma. N Engl J Med. 2013; 369(2):122-33.

17. Gibney GT, Kudchadkar RR, DeConti RC, Thebeau MS, Czupryn MP, Tetteh $\mathrm{L}$, et al. Safety, correlative markers, and clinical results of adjuvant nivolumab in combination with vaccine in resected high-risk metastatic melanoma. Clin Cancer Res. 2015; 21(4):712-20.

18. Carbognin L, Pilotto S, Milella M, Vaccaro V, Brunelli M, Caliò A, et al. Differential Activity of Nivolumab, Pembrolizumab and MPDL3280A according to the Tumor Expression of Programmed Death-Ligand-1 (PD-L1): Sensitivity Analysis of Trials in Melanoma, Lung and Genitourinary Cancers. PLoS One. 2015; 10(6):e0130142.

19. Rizvi NA, Mazières J, Planchard D, Stinchcombe TE, Dy GK, Antonia SJ, et al. Activity and safety of nivolumab, an anti-PD-1 immune checkpoint inhibitor, for patients with advanced, refractory squamous non-small-cell lung cancer (CheckMate 063): a phase 2, single-arm trial. Lancet Oncol. 2015; 16(3):257-65.

20. Voena C, Chiarle R. Advances in cancer immunology and cancer immunotherapy. Discov Med. 2016; 21(114):125-33.

21. Kazandjian D, Suzman DL, Blumenthal G, Mushti S, He K, Libeg M, et al. FDA Approval Summary: Nivolumab for the Treatment of Metastatic Non-Small Cell Lung Cancer With Progression On or After Platinum-Based Chemotherapy. Oncologist. 2016; 21(5): 634-42.

22. [No authors listed]. Dramatic Survival Benefit with Nivolumab in Melanoma. Cancer Discov. 2016 Apr 18.

23. Asmar R, Yang J, Carvajal RD. Clinical utility of nivolumab in the treatment of advanced melanoma. Ther Clin Risk Manag. 2016; 12:313-25.

24. Brahmer JR, Hammers H, Lipson EJ. Nivolumab: targeting PD-1 to bolster antitumor immunity. Future Oncol. 2015; 11(9):1307-26.

25. Raedler LA. Opdivo (Nivolumab): Second PD-1 Inhibitor Receives FDA Approval for Unresectable or Metastatic Melanoma. Am Health Drug Benefits. 2015; 8 (Spec Feature):180-3.

26. Barbee MS, Ogunniyi A, Horvat TZ, Dang TO. Current status and future directions of the immune checkpoint inhibitors ipilimumab, pembrolizumab, and nivolumab in oncology. Ann Pharmacother. 2015; 49(8):907-37.

27. Agrawal S, Feng Y, Kollia G, Saeger S, Ullmann M, McDonald D, et al. Clinical pharmacokinetics (PK) of BMS-936558, a fully human anti-PD-1 monoclonal antibody. J Clin Oncol. 2012, 30(15): AbstractTPS2622.
28. Rounds A, Kolesar J. Nivolumab for second-line treatment of metastatic squamous non-small-cell lung cancer. Am J Health Syst Pharm. 2015; 72 (21): 1851-5.

29. de Mello RA, Pousa I, Pereira D. Nivolumab for advanced squamous cell lung cancer: what are the next steps? Lancet Oncol. 2015; 16(3):234-5.

30. Sundar R, Cho BC, Brahmer JR, Soo RA. Nivolumab in NSCLC: latest evidence and clinical potential. Ther Adv Med Oncol. 2015; 7(2):85-96

31. Brahmer JR, Horn L, Antonia SJ. Survival and long-term follow-up of the phase I trial of nivolumab (Anti-PD-1; BMS-936558; ONO-4538) in patients (pts) with previously treated advanced non-small cell lung cancer (NSCLC). J Clin Oncol. 2013, 31:Abstract8030.

32. Brahmer JR, Horn L, Gandhi L. Nivolumab (anti-PD-1, BMS-936558, ONO-4538) in patients (pts) with advanced non-small-cell lung cancer (NSCLC): Survival and clinical activity by subgroup analysis. J Clin Oncol. 2014, 32:Abstract8112.

33. Rajan A, Gulley JL. Nivolumab (anti-PD-1, BMS-936558, ONO-4538) in patients with advanced non-small cell lung cancer. Transl Lung Cancer Res. 2014; 3(6): 403-5.

34. Gettinger SN, Shepherd FA, Antonia SJ, Brahmer JR, Chow LQM, Juergens RA, et al. First-line nivolumab (anti-PD-1; BMS-936558, ONO-4538) monotherapy in advanced NSCLC: safety, efficacy, and correlation of outcomes with PD-L1 status. J Clin Oncol. 2014; 32:Abstract8024.

35. Antonia SJ, Brahmer JR, Gettinger SN, Chow LQM, Juergens RA, Shepherd FA, et al. Nivolumab (anti-PD-1; BMS-936558, ONO-4538) in combination with platinum-based doublet chemotherapy (PT-DC) in advanced non-small cell lung cancer (NSCLC). J Clin Oncol. 2014; 32:Abstract8113.

36. Raedler LA. Opdivo (Nivolumab): Second PD-1 Inhibitor Receives FDA Approval for Unresectable or Metastatic Melanoma. Am Health Drug Benefits. 2015; 8(Spec Feature):180-3.

37. Johnson DB, Peng C, Sosman JA. Nivolumab in melanoma: latest evidence and clinical potential. Ther Adv Med Oncol. 2015; 7(2):97-106.

38. Weber JS, Kudchadkar RR, Yu B, Gallenstein D, Horak CE, Inzunza HD, et al. Safety, efficacy, and biomarkers of nivolumab with vaccine in ipilimumab-refractory or -naive melanoma. J Clin Oncol. 2013; 31(34):4311-8.

39. Mashima E, Inoue A, Sakuragi $Y$, Yamaguchi T, Sasaki N, Hara $Y$, et al. Nivolumab in the treatment of malignant melanoma: review of the literature. Onco Targets Ther. 2015; 8:2045-51.

40. Wolchok JD, Kluger H, Callahan MK, Postow MA, Rizvi NA, Lesokhin AM, et al. Nivolumab plus ipilimumab in advanced melanoma. N Engl J Med. 2013; 369(2):122-33.

41. Seles M, Hutterer GC, Kiesslich T, Pummer K, Berindan-Neagoe I, Perakis S, et al. Current Insights into Long Non-Coding RNAs in Renal Cell Carcinoma. Int J Mol Sci. 2016; 17(4): E573.

42. Lee $\mathrm{CH}$, Motzer RJ. Immune Checkpoint Therapy in Renal Cell Carcinoma. Cancer J. 2016: 22(2):92-5.

43. Gunturi A, McDermott DF. Nivolumab for the treatment of cancer. Expert Opin Investig Drugs. 2015; 24(2):253-60.

44. Drake CG, McDermott DF, Sznol M, Choueiri TK, Kluger HM, Powderly J D, et al. Survival, safety, and response duration results of nivolumab (Anti-PD-1; BMS-936558; ONO-4538) in a phase I trial in patients with previously treated metastatic renal cell carcinoma (mRCC): Long-term patient follow-up. J Clin Oncol. 2013. 31:Abstract4514.

45. Carlo-Stella C, Santoro A. Microenvironment-related biomarkers and novel targets in classical Hodgkin's lymphoma. Biomark Med. 2015; 9(8):807-17.

46. Bagcchi S. Nivolumab shows clinical activity in Hodgkin's lymphoma. Lancet Oncol. 2015; 16(3):e108.

47. Ansell SM, Lesokhin AM, Borrello I, Halwani A, Scott EC, Gutierrez M, et al. PD-1 blockade with nivolumab in relapsed or refractory Hodgkin's lymphoma. N Engl J Med. 2015; 372(4):311-9.

48. Rizvi NA, Mazières J, Planchard D, Stinchcombe TE, Dy GK, Antonia SJ, et al. Activity and safety of nivolumab, an anti-PD-1 immune checkpoint inhibitor, for patients with advanced, refractory squamous non-small-cell lung cancer (CheckMate 063): a phase 2, single-arm trial. Lancet Oncol. 2015; 16(3):257-65.

49. Postow MA, Chesney J, Pavlick AC, Robert C, Grossmann K, McDermott D, et al. Nivolumab and ipilimumab versus ipilimumab in untreated melanoma. $\mathrm{N}$ Engl J Med. 2015; 372(21):2006-17.

50. Motzer R, Rini BI, McDermott DF, Redman BG, Kuzel TM, Harrison MR, et al. Nivolumab for Metastatic Renal Cell Carcinoma: Results of a Randomized Phase II Trial. J Clin Oncol. 2015; 33(13): 1430-7.

51. Hamanishi J, Mandai M, Ikeda T, Minami M, Kawaguchi A, Murayama T, et al. Safety and Antitumor Activity of Anti-PD-1 Antibody, Nivolumab, in Patients with Platinum-Resistant Ovarian Cancer. J Clin Oncol. 2015; 33(34):4015-22.

52. Brahmer J, Reckamp KL, Baas P, Crinò L, Eberhardt WE, Poddubskaya E, et al. Nivolumab versus Docetaxel in Advanced Squamous-Cell Non-Small-Cell Lung Cancer. N Engl J Med. 2015; 373(2): 123- 35.

53. Yaqub F. Nivolumab for squamous-cell non-small-cell lung cancer. Lancet Oncol. 2015; 16(7):e319.

54. Robert C, Long GV, Brady B, Dutriaux C, Maio M, Mortier L, et al. Nivolumab in previously untreated melanoma without BRAF mutation. N Engl J Med. 2015; 372(4):320-30

55. Weber JS, D'Angelo SP, Minor D, Hodi FS, Gutzmer R, Neyns B, et al. Nivolumab versus chemotherapy in patients with advanced melanoma who progressed after anti-CTLA-4 treatment (CheckMate 037): a randomised, controlled, open-label, phase 3 trial. Lancet Oncol. 2015; 16(4):375-84 
56. Larkin J, Chiarion-Sileni V, Gonzalez R, Grob JJ, Cowey CL, Lao CD, et al. Combined Nivolumab and Ipilimumab or Monotherapy in Untreated Melanoma. N Engl J Med. 2015; 373(1): 23-34.

57. Falchook G. Nivolumab: another weapon in the growing immunotherapy arsenal. Lancet Oncol. 2015; 16(4):350-1.

58. Motzer RJ, Escudier B, McDermott DF, George S, Hammers HJ, Srinivas S, et al. Nivolumab versus Everolimus in Advanced Renal-Cell Carcinoma. N Engl J Med. 2015; 373(19):1803-13.

59. Worley L. Cabozantinib and nivolumab for renal cell carcinoma. Lancet Oncol. 2015; 16(15):e531. 